\title{
Intracranial Ependymomas in Children: The Role of Surgery And Adjuvant Treatment.
}

\author{
K.Bouaita, Shabay.Z, N.Ioualalen \\ Department Of Neurosurgery, Hospital Ali Ait Idir, University Of Algeries, Algeria
}

\begin{abstract}
The management of pediatric intracranial meningiomas poses a big challenge. We are presenting the role of extent of tumor resection and adjuvant therapy in the survival of children with ependymomas. This is a retrospective study of 56 children with non-metastatic intracranial ependymomas treated between 2010 and 2015.The mean age was 8 years ranging between 3 months and 15 years. The most frequent location was infra tentorial location in $67.8 \%$ of patients.

Total tumor resection was possible in $42.8 \%$ (25 patients)while partial resection was performed in $35.7 \%$ More than half of the patients were between WHO histological grade I and II (Grade I: 12 patients and Grade II: 18 patients) while $44.6 \%$ of tumors were anaplasic ependymomas (Grade III: 25 patients).

More than half of the patients have received radiotherapy as initial adjuvant treatment (55.3\%), while less than half of all patients have received chemotherapy (21.4\%).

Four children have received radiotherapy and chemotherapy.Morbidity experienced included six patients CSF leakage, four patients meningitis and nine patients with neurologic deterioration, 2 patients with seizures and 2 patients with intraventricular hemorrhage. There were four deaths after 38 months follow up and all our patients were followed up for 05 years.
\end{abstract}

Keywords: Chemotherapy.surgery, survival, radiotherapy, recurrent tumor.

\section{Introduction}

Ependymomas are neuro-epithelial tumours and are derived from aneoplasic transformation of ependymal cellules which covers theventricular system; they belong to the group of glial tumours. They represent 2 to $9 \%$ of all intracranial tumours and above $12 \%$ of pediatric brain tumours of which $75 \%$ of cases are located in the posterior cerebral fossa $(1,2,3)$.The $1^{\text {st }}$ histologic description of an ependymoma goes back to VIRCHOW In 1864.BAILEY And CUSHING in 1926 classified them among the glial tumours(1).

The PCF ependymomas predominate in young children, while the supratentorial localisations are seen mainly in older children, adolescents andadults $(1,2,3)$.Is reflected by a clinically Intracranial hypertension,cerebellar syndrome and other focal signs.The insertion is mostly at the floorof V4(80\%) and more specifically at the bulbar triangle where vital structures are located, they may extend into the cisterna magnumvia the foramen of MAGENDIE then to cervical subarachnoidspaces. Their extension to the cerebellopontine angle and mixed nerves is possible via the foramen of Luschka.The upper extension to the V3 is exceptional and can be done via the aqueduct of SYLVIUS. Their treatment is surgery followed by radiotherapy and / or chemotherapy as adjuvant therapy (2-4-5).Besides the problem of incomplete resection often due to their location, theirprognosis is difficult to identify because of the risk of recurrence or neurological grafts away from the original focus by fluid channels. (5). The contribution of radiotherapy in the treatment of tumourrecurrence is as important as in anaplastic forms (2-6).

\section{Patients And Methodes}

This is a retrospective study of 56 patients operated between 2010 and 2015 at Ali aitIdir Hospital in Algiers.There exists a female predominance ( 29 girls vs 27 boys), with mean age of 08 years and age extremes between 3 months and 15 years.

Clinical presentation :multiple forms(Table I),

\section{Results}

Location: the most frequent location is infra-tentorial, found in $67.8 \%$ of the cases (36 cases), while the supratentorial location was found in 18 patients, or $32.2 \%$ of the cases.

Among the infra-tentorial lesions, there are:

* 18 cases of ependymomas of the floor of the fourth ventricle (fig1).

* 04 cases of ependymomas with extension towards the bulbo-medullary junction and up to the second cervical vertebra.

* 12 cases of ependymomas of the roof of the fourth ventricle.

* 07 cases at the level of the lateral recess with an extension towards the cerebello pontine angle (fig2). 
The supra-tentorial location includes:

* 11 cases in the lateral ventricles (fig 3 ),

* 01 case of para ventricular ependymoma.

* 06 cases of para and intra-ventricular ependymoma (Fig 4).

Excision quality: Postoperative imaging (CT or MRI) was performed to evaluate the quality of surgical excision, the majority of the patients benefited from an immediate postoperative brain CT scan and a distant MRI.Total tumor resection was obtained in $42.8 \%$ of the cases (25 cases) whereas partial resection was performed in $35.7 \%$ of the cases, their location was essentially infratentorial.

Histologic group: more than half of the patients are myxopapillary ependymomas or sub-ependymomas. 12 cases were grade I and 18 cases were WHO grade II.

The others (25 cases), or 44.6\%, are grade III anaplastic ependymomas.

Adjuvant treatment:More than half of the patients $(55.3 \%)$ received radiotherapy as an initial adjuvant therapy, while less than half of the patients $(21.4 \%)$ received chemotherapy.4 children received concomitant radiotherapy with chemotherapy.

Morbidity: the postoperative period was marked by the following complications;

* 6 cases of CSFleakage, following surgery of the posterior fossaependymomas, were treated by lumbar punctures, of which four were complicated by meningitis treated by adapted antibiotherapy.

* Only one case presented a cervical metastasis, was operated some months after the first histopathological results confirmed the ependymal nature.

* Two patients presented post-operative intracranial hypertension syndrome secondary to a VP shunt dysfunction.

* Nine patients had neurological deterioration, including 2 cases of epilepsy and 2 cases of intraventricular hemorrhage.

Pronostic: All of our patients were regularly monitored for 36 months, especially those with partial tumor excision and received radiotherapy with or without chemotherapy; Their tumor residue remained stable and was followed periodically by both the neurosurgeon and the oncologist.

Two cases of supratentorialependymomas have recurred late; And underwent surgical resection with adjuvant chemotherapy.Wedeplore the death of 4 children, occurringwithin an average of 38 months

The survival :

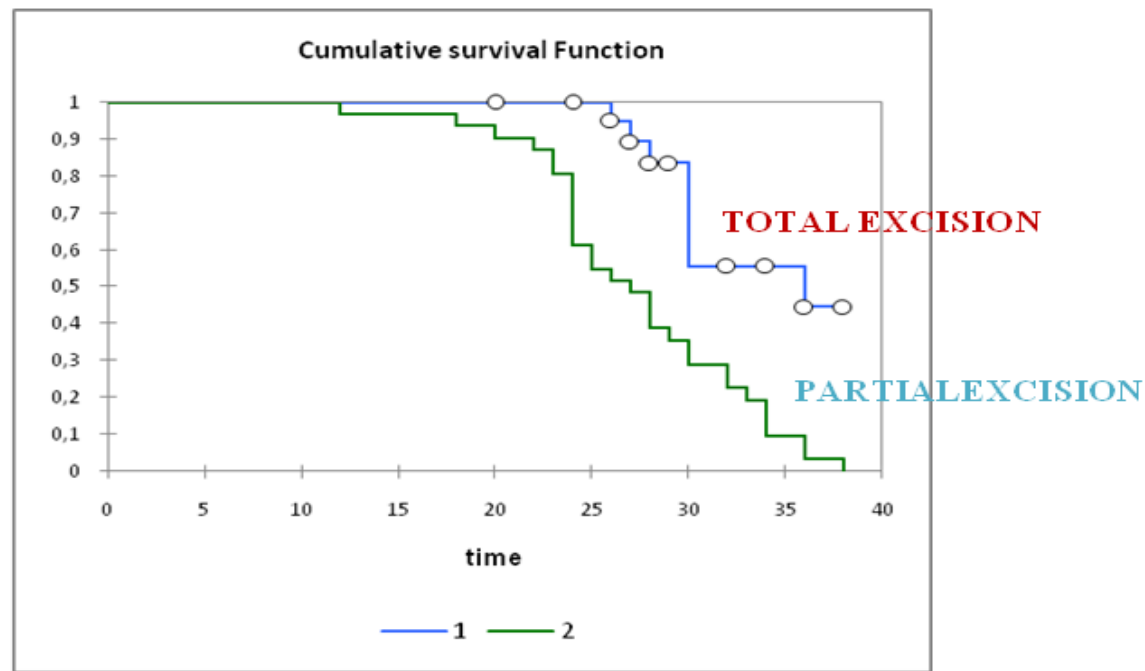

1: survival of patients with partial resection.

2: survival of patients with total resection.

We found on the kaplainmeyer survival curves that the survival of children who underwent surgery with total tumor resection is significantly better compared to those who underwent partial resection with p-value $<0.0001$.

\begin{tabular}{|l|l|l|l|l|}
\hline Statistic & observedValue & criticalValue & p-value & Alpha \\
\hline Log-rank & 15,995 & 3,841 & $<\mathbf{0 , 0 0 0 1}$ & 0,050 \\
\hline Wilcoxon & 14,693 & 3,841 & 0,000 & 0,050 \\
\hline Tarone-Ware & 15,378 & 3,841 & $<0,0001$ & 0,050 \\
\hline
\end{tabular}

IV. Discussion 
Intracerebral ependymomas represent $3^{\text {rd }}$ most frequent central nervous system tumours in children. While they can occur at any age, $50 \%$ are diagnosed in children under 05 years, and usually are located in the PCF (70-80\%). In adults, they are usually cortical $(6,7.8)$.

In our series, the infratentorial location or posterior fossa is the most common in $67.8 \%$ of cases.

In small children, it is more likely to be histologically malignant, it is not the same in children 10 to 15 years where it is rather benign (9-10). The close relationship with the brainstem andmixed cranial nerves, makes it difficult for surgical resection. This often presents a dilemma to try a total resection and the potential morbidity, but many studies show that a total resection provides better control of long-term disease.

Ikezaki et al believe that the location of the tumor and its volume are important prognostic factors for ependymoma of the posterior fossa, hence their classification into three types: ependymoma of the roof and floor and also ependymoma of lateral recess. In the latter position the tumor ensheaths the cranial nerves IX, X, XI and XII and adheres to the brainstem (10). Most authors agree that the anaplastic variety is of poor prognosis, but the results for the other histological types of ependymoma vary. Also described less than 5\% of ependymomas are widespread at diagnosis, this character is not usually considered in the classification of patients. On the contrary, biological markers are under study and could be good predictors of prognosis.

One of the most important challenge for intracranial ependymoma is to determine optimal multimodal treatment.

Currently all authors agree for the surgery with total resection followed by radiation therapy. In the series published by Sutton et al, 05 years survival was $60 \%$ for patients who underwent total or subtotal excision against $21 \%$ for children who underwent partial resection or biopsy (11).

In our series, survival at 5 years was $88 \%$ after total surgical resection followed by radiation therapy.

Surgery plays an important role in the treatment of ependymomas and it is clear that the quality of resection influences the prognosis. However, surgery is rarely curative and recurrence are mostly local.

In our series, total excision in $42.8 \%$ of cases (25cases) while the partial resection in $35.7 \%$ of cases.

Shu et al report a survival rate of 40.7 to $66.2 \%$ and a median follow-up of 110, 2 months, 49 children treated Children's Hospital of Philadelphia and of university of Pensylvania (10). Mansur et al: tracking 10 years of 60 patients with a survival rate of 49,5-55\% in Washington Universityschool of medicine with a median survival of 12.5 years (13) Paulino et al: Monitoring during 9,6 years of 49 children and a survival rate of 603 to $71.4 \%$ with 05 years local control (6) See Table N03.

Conventional radiotherapy has good results in tumor control after maximal resection. This must include the brain stem and cervical cord. It would have little neurocognitive effects according to the literature $(14,17$, 18,19). The benefit of chemotherapy for children is far from proven. Studies have suggested that there is no benefit to adding adjuvant chemotherapy during or after radiotherapy. Recently, other studies have shown its effectiveness before radiotherapy in anaplastic ependymoma (20). Some have tried to use chemotherapy to delay the need for radiation therapy especially in vulnerable patients to the deleterious effects of radiation such as young children. There is no consensus regarding the age when we begin radiation therapy. Some have used conventional radiotherapy in children of 01 year; others suggested the use of chemotherapy to delay radiation therapy until the age of 03 years $(21,22)$. The ependymoma in children is one of the most frustrating conditions for the neurosurgeon in terms of prognosis. Apart from the role of: age, location, extent of resection, histology and effectiveness of complementary treatments, these factors are insufficient to tell the true prognosis.

Currently we speak of molecular biology that could lead to risk groups with overall survival. Thus the therapeutic strategy could be more focused (23).

Figures and Tables:

Table I: frequency of clinical symptoms.

\begin{tabular}{|l|l|}
\hline Semiology & number \\
\hline Intracranial Hypertension & 50 cases \\
\hline Cerebellar Syndrome & 28 cases \\
\hline Motor Deficits & 11 cases \\
\hline Macrocephaly & 12 cases \\
\hline Epileptic seizures & 04 cases \\
\hline Frontal lobe Syndrome & 02 cases \\
\hline Coma & 08 cases \\
\hline
\end{tabular}

Table ${ }^{\circ}$ II : Patients Characteristics And Their Treatment Details

\begin{tabular}{|l|l|}
\hline PATIENTS & NUMBER \\
\hline Sex $\quad$-boys : & \\
$\quad$-girls: & 27 \\
WHO Grade & 29 \\
\hline -grade I & 13 \\
\hline
\end{tabular}


Intracranial Ependymomas In Children: The Role Of Surgery And Adjuvant Treatment.

\begin{tabular}{|l|l|}
\hline \multicolumn{1}{|c|}{-grade II } & 18 \\
-grade III & 25 \\
\hline Tumor location & \\
-infra-tentorial & 38 \\
-supra-tentorial & 18 \\
\hline Extent of tumor resection & \\
- subtotal or partial resection & 31 \\
- total resection & 25 \\
\hline Chemotherapy & 12 \\
Radiotherapy & 31 \\
Radio-chemotherapy & 04 \\
\hline
\end{tabular}

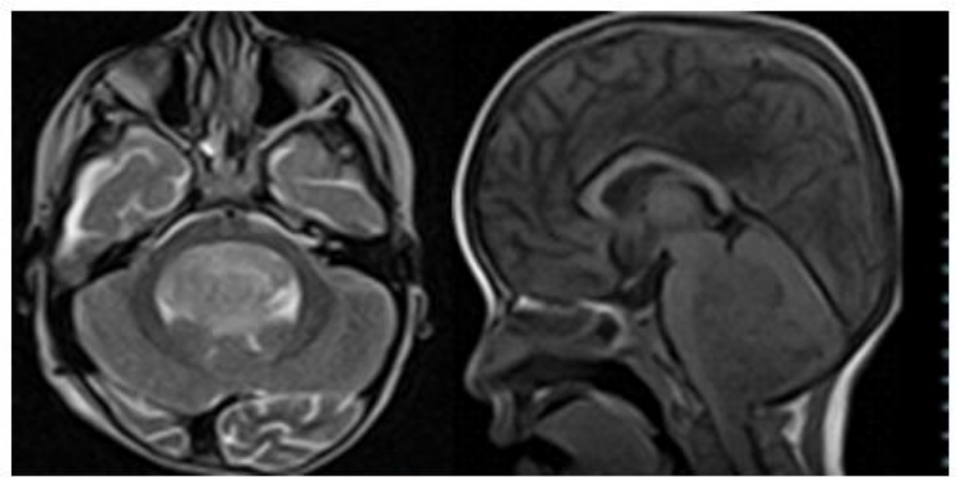

A
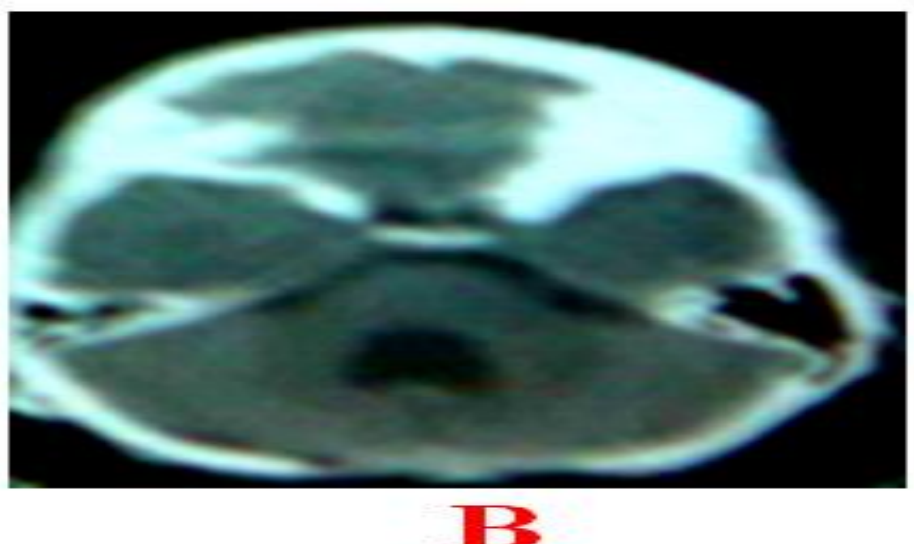

Fig 1:

A-preoperative MRI images in sagittal and axial sections showing a large ependymoma of the posterior cerebral fossa with cisternal extension.

B-a ct scanimagein immediate postoperative period showing the quality of excision.

Two-yearfollow-up and postoperativeradiotherapy. 


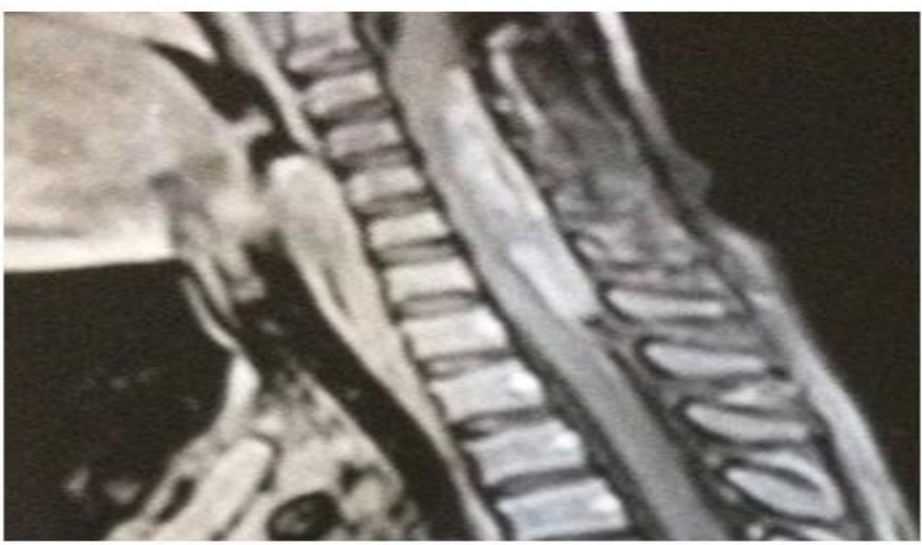

C

C : Images of a cervical MRI in sagittal section showing the appearance of a cervical ependymoma in the same patient afterthreeyears of follow-up.
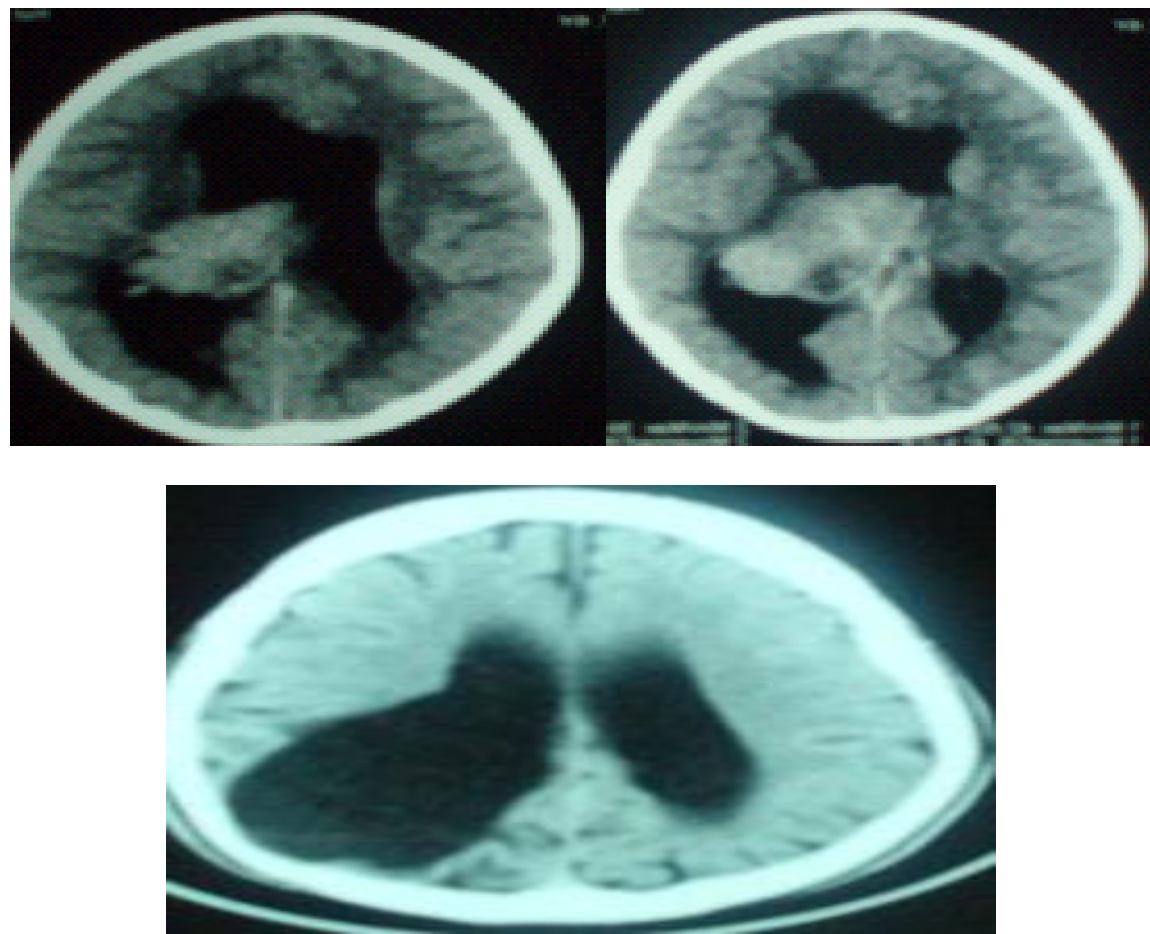

Fig 2 :Images of an intraventricular ependymoma.

The control ct scan after 04 years of intervention.

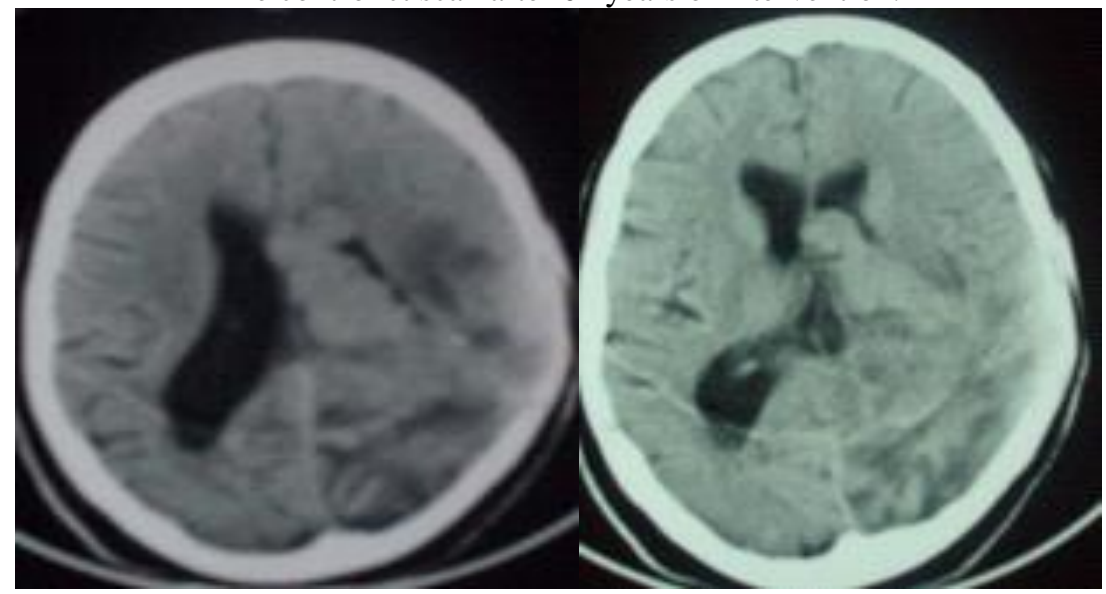




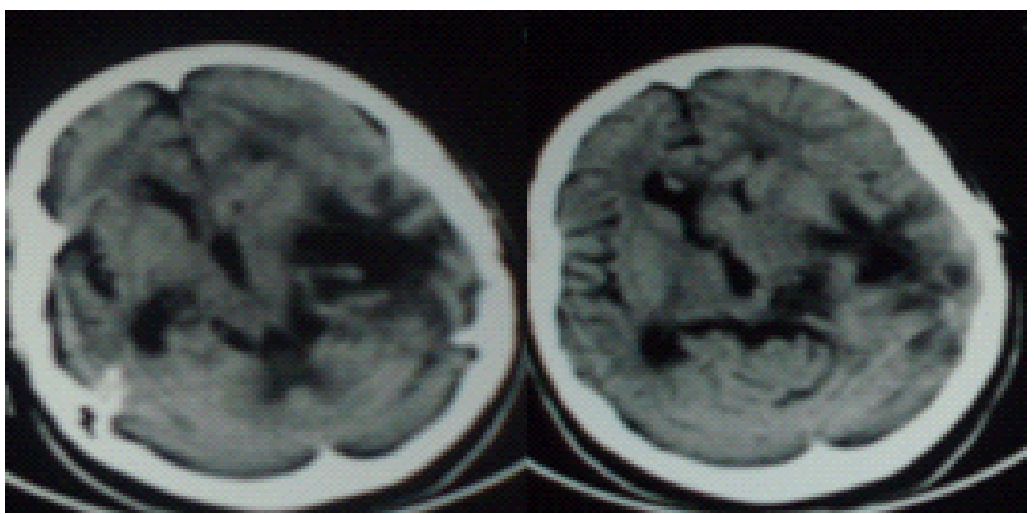

Fig3 :Preoperative and postoperative scannographic images of an intra -ventricular ependymoma.
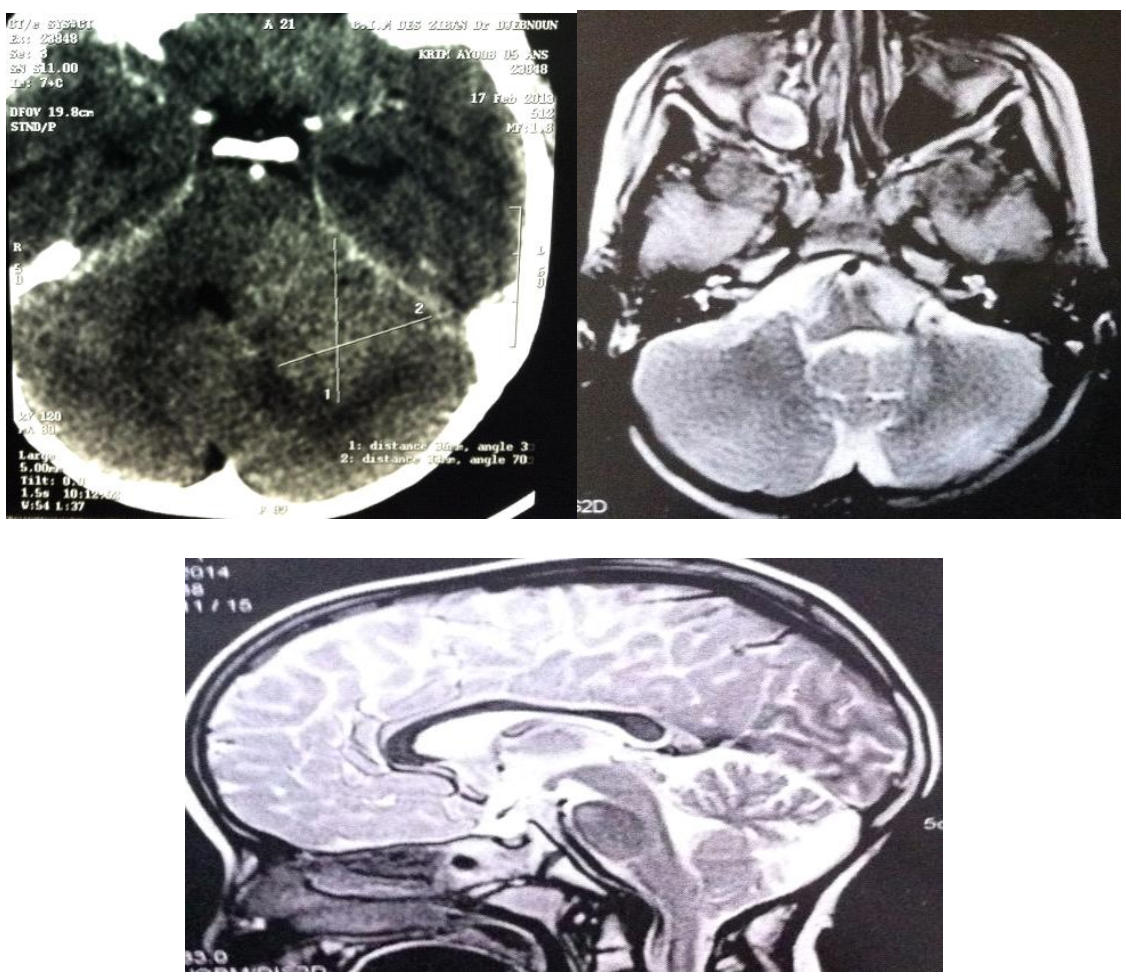

Fig4

Fig4 :-preoperativectscan images ofan ependymoma of the roof of fourth ventricle with extension towards the cerebello pontine angle.

- MRI images in axial and sagittal sections showing the quality of excision after a follow-up of twoyears and postoperativeradiotherapy.

\section{Conclusion}

Ependymomas are relatively aggressive tumors that are resistant to adjuvant treatments. The severity observed in the development of ependymomas is the risk of recurrence and liquid metastasis. Their situation in the ventricular cavity makes complete surgical resection difficult, but it seems like the best way to get a prolonged survival. Conversely, complete resection may cause heavy consequences. Adjuvant radiotherapy for low-risk patients who have undergone complete resection is a reasonable treatment option.

\section{References}

[1]. Frederick A. Boop\& Spyros Sgouros:Intracranialependymoma in children: current status and future trends on diagnosis and management.ChildsNervSyst (2009) 25:1163-1165.

[2]. SunandaPejavar $\bullet$ Mei-YinPolley $\bullet$ Sarah Rosenberg-Wohl et al:Pediatric intracranial ependymoma: the roles of surgery, radiation and chemotherapy.

[3]. J Neurooncol (2012) 106:367-375.

[4]. Rousseau P, Habrand JL, Sarrazin D et al:Treatment of intracranial ependymomas of children: review of a 15 -year experience.Int J RadiatOncolBiolPhys(1993) 28:381-386. 
[5]. G. Tamburrini\& M. D’Ercole\& B. L. Pettorini\& M.et al: Survival following treatment for intracranial ependymoma: a review.

[6]. Childs NervSyst (2009) 25:1303-1312.

[7]. Andrew S. Little \& Tyson Sheean\&RagavanManoharan et al:The management of completely resected childhood intracranial ependymoma: the argument for observation only.ChildsNervSyst (2009) 25:281-284

[8]. Mansur DB, Perry A, Rajaram V, Michalski JM, Park TS, Leonard JR et al Postoperative radiation therapy for grade II and III intracranial ependymoma. Int J RadiatOncolBiol Phys (2005) 61:387-391

[9]. Shu HK, Sall WF, Maity A, Tochner ZA, Janss AJ, Belasco JB et al :Childhood intracranial ependymoma: twenty-year experience from a single institution. Cancer (2007) 110:432-441

[10]. Paulino AC, Wen BC, Buatti JM, Hussey DH, Zhen WK, Mayr NA et al : Intracranial ependymomas: an analysis of prognostic factors and patterns of failure. Am J ClinOncol(2002)25:117-122.

[11]. McGuire CS, Sainani KL, Fisher PG Both:location and age predict survival in ependymoma: a SEER study.Pediatr Blood Cancer (2009)52:65-69.

[12]. Massimino M, Gandola L, Giangaspero F, Sandri A et al; Hyperfractionated radiotherapy and chemotherapy for childhood ependymomas: final results of the first prospective AIEOP.Int J RadiatOncolBiolPhys (2004) 58:1336-1345

[13]. Perilongo G, Massimino M, Sotti G et al:Analysis of prognostic factors in a retrospective review of 92 children with ependymomas: Italian Pediatric Neurooncology Group. Med PediatrOncol(1997) 29:79-85

[14]. Robertson PL, Zeltzer PM, Boyett JM et al: Survival and prognostic factors following radiation therapy and chemotherapy for ependymomas in children: a report of the Children's Cancer Group. J Neurosurg (1998) 88:695-703 13.

[15]. Schroeder TM, Chintagumpala M, Chiu JK, Teh BS, Woo SY, Paulino AC Intensity-modulated radiation therapy in childhood ependymomas.Int J RadiatOncolBiol(2008) 71:987-993 15.

[16]. Mulhern RK, Merchant TE, Gajjar A, Reddick WE, Kun LE: Late neurocognitive sequelae in survivors of brain tumours in childhood. Lancet Oncol(2004) 5:399-408.

[17]. Ikezaki K, Matsushima $\mathrm{T}$, Inoue $\mathrm{T}$ et al: Correlationofmicroanatomical localization with postoperative survival in posterior fossa ependymomas. Neurosurgery (1993) 32:38-44.

[18]. Sutton LN, Goldwein J, Perilongo G, Lang B, Schut L, Rorke L et al:Prognostic factors in childhood ependymomas. PediatrNeurosurg(1990)16:57-65.

[19]. Copeland DR, deMoor C, Moore BD 3rd, AterJL: Neurocognitive development of children after a cerebellar tumor in infancy: a longitudinal study. J ClinOncol (1999)17:3476-3486.

[20]. Riva D, Giorgi C:The neurodevelopmental price of survival in children with malignant brain tumours. Childs NervSyst (2009)16:751-754.

[21]. Spiegler BJ, Bouffet E, Greenberg ML, Rutka JT, MabbottDJ:Change in neurocognitive functioning after treatment with cranial radiation in childhood. J ClinOncol (2004) 22:706-713.

[22]. Grill J, Le Deley MC, Gambarelli D et al: Postoperative chemotherapy without irradiation for ependymoma in children under 5 years of age: a multicenter trial of the French Society of Pediatric Oncology. J ClinOncol (2001) 19:1288-1296.

[23]. Matthew Koshy • Shayna Rich • Thomas E. Merchant • Usama Mahmood • William F. Regine • Young Kwok:Post-operative radiation improves survival in children younger than 3 years with intracranial ependymoma.JNeurooncol (2011) 105:583-590

[24]. Grundy RG, Wilne SA, Weston CI, et al: Primary postoperative chemotherapy without radiotherapy for intracranial ependymoma in children: the UKCCSG/SIOP prospective study. Lancet Oncol 2007, 8:696-705.

[25]. J-H. Kim - Y. Huang - A. S. Griffin - P. Rajappa - J. P. Greenfield:Ependymoma in children: molecular considerations and therapeutic insights.ClinTranslOncol (2013) 15:759-765 